\title{
AUC Infinity Predicted Normalized by
}

\section{Surface Area}

National Cancer Institute

\section{Source}

National Cancer Institute. AUC Infinity Predicted Normalized by Surface Area. NCI

Thesaurus. Code C92320.

The area under the curve (AUC) extrapolated to infinity from dosing time, based on the predicted last concentration, divided by the surface area. 